\title{
DETERMINASI KUALITAS PELAYANAN: RELIABILITHY, ASSURANCE, TANGIBLE, EMPATHY, RESPONSIVENESS TERHADAP KEPUASAN PELANGGAN (Studi Kasus Pada J\&T Express Lamongan)
}

\author{
*(Priyanto Adi Wibowo ${ }^{1}$, Abid Muhtarom ${ }^{2}$ \\ Prodi Manajemen, Fakultas Ekonomi, Universitas Islam Lamongan \\ $\mathrm{Jl}$. Veteran No.53A Lamongan \\ Telp. ( 0322 ) 324706, Faks. ( 0322 ) 324706 \\ Email :jpim@unisla.ac.id
}

\begin{abstract}
ABSTRAK
$J \& T$ Epress Lamongan sebagai objek penelitian karena merupakan pusat dari $J \& T$ Express di wilayah Lamongan. Tujuan dari penelitian ini untuk mengetahui pengaruh kualitas layanan terhadap kepuasan pelanggan baik secara bersamasama ataupun sebagian pada PT. J\&T Express Lamongan.

Jenis penelitian yang digunakan dalam penelitian ini adalah penelitian deskriptif yang menggunakan pendekatan kuantitatif. Teknik analisa yang digunakan adalah teknik analisa deskriptif dan dengan menggunakan regresi berganda. Sedangkan sampel teknik yang digunakan adalah accidental sampling sampel yang menggunakan total sampel sebesar 78 orang. Berdasarkan hasil dari penelitian ini bahwa kualitas layanan (X) yang terdiri dari Reliabilithy, Assurance, Tangible, Empathy, Responsiveness memiliki pengaruh signifikan terhadap kepuasan pelanggan dengan nilai (nilai p) $0.000<0.05$. Sebagian hasil uji menunjukkan bahwa hanya variabel Reliabilithy yang memiliki sebagian pengaruh dalam kepuasan pelanggan dengan jumlah variabel yang signifikan (nilai p) berjumlah $0.000<0.05$. Metode yang digunakan dalam penelitian ini adalah deskriptif kuantitatif, sedangkan alat yang digunakan untuk menganalisis data permasalahan yang ada yaitu menggunakan Uji Validitas, Uji Reliabilitas, Uji Regresi Linier Berganda, Koefisien Determinasi, Uji t, Uji F.

Hasil penelitian kualitas pelayanan (Reliabilithy, Assurance, Tangible, Empathy, Responsiveness) secara parsial dan simultan berpengaruh positif dan signifikan terhadap kepuasan pelanggan dan variabel Reliabilithy $\left(X_{1}\right)$ merupakan variabel yang lebih dominan dalam mempengaruhi kepuasan pelanggan.
\end{abstract}

Kata kunci : Kualitas Pelayanan, Reliabilithy, Assurance, Tangible, Empathy, Responsiveness dan Kepuasan Pelanggan

\section{Latar Belakang}

Dalam era globalisasi ini persaingan bisnis sangat ketat, baik di pasar domestik maupun din pasar internsioanal. Salah satu tantangan terbesar dalam dunia bisnis di era ini adalah mempeertahankan pelanggan yang puas dan loyal. Salah satu hal terepenting dalam bidang jasa yang harus diperhatikan oleh perusahaan agar dapat menarik dan 
mempertahankan pelanggan yaitu kualitas pelayanan.

Masih banyak pelayanan yang tidak sesuai dengan harapan konsumen, sehingga membuat kualitas jasa yang dihasilkan sangat rendah dan tidak memuaskan konsumen. Hal ini membuat pelayanan perusahaan tersebut menjadi buruk di mata para konsumen dan akhirnya merugikan perusahaan itu sendiri.

J\&T Express sebagai perusahaan yang bergerak dalam bidang jasa dituntut untuk memberikan pelayanan yang berkualitas kepada pelanggannya. Keputusan pelanggan untuk menggunakan jasa pengiriman barang terjadi apabila kualitas pelayanan pada perusahaan pengiriman barang tersebut sesuai dengan apa yang diharapkan pelanggan.

J\&T Epress Lamongan berada di Jalan Kusuma Bangsa No 34 Lamongan. Lokasi ini di pilih sebagai objek penelitian karena merupakn pusat dari J\&T Express di wilayah Lamongan.

Beberapa penelitian telah dilakukukan untuk mengetahui faktor-faktor kualitas pelayanan yang berpengaruh terhadap kepuasan pelanggan di berbagai perusahaan. Panjaitan, Efendi, Januar, ec al (2016) mengkaji pengaruh kualitas pelayanan terhadap kepuasan pelanggan pada JNE Cabang Bandung. Penelitian Tri Hari Koestanto.ec.al (2014) mengkaji pengaruh kualitas pelayanan terhadap kepuasan pelanggan pada Bank Jatim Cabang Klampis Surabaya. Penelitian ini berjudul Analisis Faktor-Faktor Kualitas Pelayanan Terhadap Kepuasan Pelanggan Pada PT. J\&T Express Lamongan. Tujuan dari penelitian ini untuk mengetahui pengaruh kualitas layanan terhadap kepuasan pelanggan baik secara bersama-sama ataupun sebagian pada PT. J\&T Express Lamongan.

\section{METODELOGI}

Penelitian ini adalah penelitian deskriptif yang menggunakan pendekatan kuantitatif. Teknik analisa yang digunakan adalah teknik analisa deskriptif dan dengan menggunakan regresi berganda. Sedangkan sampel teknik yang digunakan adalah accidental sampling. Data yang di dapat akan di olah menggunakan alat statistika menurut Sugiyono (2015).

Data pelanggan J\&T Express yang digunakan dalam penelitian. Data penenlitian ini bersumber dari J\&T Express Lamongan. Data kuisioner yang digunakan dalam penelitian. Data ini bersumber dari jawaban responden pelanggan J\&T Express Lamongan menurut Sugiyono (2015).

Dalam penelitian ini menggunakan alat ananlisis Uji Validitas, Uji Reliabilitas, Uji Regresi Linier Berganda, Koefisien Determinasi, Uji t, Uji F menurut Sugiyono. (2015).

Persamaan data statistik yang diporoleh dari jurnal penelitian Koestanto, Tri, Hari, et all (2015), Eva, Karla (2015), Khasanah, 
Imroatul (2010), Khatimah, Husnul (2010), dan Panjaitan, Januar,ec al (2016) dapat memmberikan informasi dan kemajuan penelian dari permasalahan antara kualitas pelayanan yang mempengaruhi kepuasan pelanggan dapat disimpulkan dalam rumus sebagai berikut :

$\mathrm{Y}=a+b_{1} X_{1}+b_{2} X_{2}+b_{3} X_{3}+b_{4} X_{4}+b_{5} X_{5}+e$

Dimana dapat disimpulkan $\mathrm{Y}=$ kepuasan pelanggan; $\mathrm{a}=$ konstanta; $\mathrm{X}_{1}=$ Reliability; $\mathrm{X}_{2}=$ Assurance $; \mathrm{X}_{3}=$ Tangible; $\mathrm{X}_{4}=$ Empathy; $\mathrm{X}_{5}=$ Responsivenes, dan $\mathrm{e}=$ error

\section{ANALISIS DAN PEMBAHASAN}

Adapun teknik analisa data yang digunakan dalam variabel ini adalah :

1. Uji Validitas,

2. Uji Reliabilitas,

3. Uji Regresi Linier Berganda,

4. Koefisien Determinasi,

5. Uji t,

6. Uji F.

Analisisnya sebagai berikut:

1. Uji Validitas

\begin{tabular}{|c|c|c|c|c|}
\hline No & Variabel/indicator & rhitung & rtabel & Keterangan \\
\hline \multirow[t]{4}{*}{1} & \multicolumn{4}{|c|}{ Reliability (X1) } \\
\hline & Indikator 1 (X1.1) & 0,75431 & 0,2272 & Valid \\
\hline & Indikator $2(\mathrm{X} 1.2)$ & 0,82277 & 0,2272 & Valid \\
\hline & Indikator 3 (X1.3) & 0,86586 & 0,2272 & Valid \\
\hline \multirow[t]{4}{*}{2} & \multicolumn{4}{|c|}{ Assurance (X2) } \\
\hline & Indikator $1(\mathrm{X} 2.1)$ & 0,87129 & 0,2272 & Valid \\
\hline & Indikator 2 (X2.2) & 0,88687 & 0,2272 & Valid \\
\hline & Indikator 3 (X2.3) & 0,87898 & 0,2272 & Valid \\
\hline \multirow[t]{4}{*}{3} & \multicolumn{4}{|c|}{ Tangibles (X3) } \\
\hline & Indikator 1 (X3.1) & 0,79345 & 0,2272 & Valid \\
\hline & Indikator 2 (X3.2) & 0,74219 & 0,2272 & Valid \\
\hline & Indikator 3 (X3.3) & 0,76263 & 0,2272 & Valid \\
\hline \multirow[t]{4}{*}{4} & \multicolumn{4}{|c|}{ Empathy (X4) } \\
\hline & Indikator 1 (X4.1) & 0,81215 & 0,2272 & Valid \\
\hline & Indikator 2 (X4.2) & 0,82343 & 0,2272 & Valid \\
\hline & Indikator 3 (X4.3) & 0,79939 & 0,2272 & Valid \\
\hline 5 & \multicolumn{4}{|c|}{ Responsiveness (X5) } \\
\hline
\end{tabular}




\begin{tabular}{|c|l|c|c|c|}
\hline \multirow{4}{*}{} & Indikator 1 (Y1.1) & 0,80221 & 0,2272 & Valid \\
\cline { 2 - 5 } & Indikator 2 (Y1.2) & 0,75798 & 0,2272 & Valid \\
\cline { 2 - 5 } & Indikator 3 (Y1.3) & 0,74383 & 0,2272 & Valid \\
\hline \multirow{3}{*}{6} & \multicolumn{3}{|c|}{ Kepuasan Pelanggan (Y) } \\
\cline { 2 - 5 } & Indikator 1 (Y1.1) & 0,837159 & 0,2272 & Valid \\
\cline { 2 - 5 } & Indikator 2 (Y1.2) & 0,711243 & 0,2272 & Valid \\
\cline { 2 - 5 } & Indikator 3 (Y1.3) & 0,620771 & 0,2272 & Valid \\
\hline
\end{tabular}

Sumber: Exel 2007, data quisoner

Dengan $\mathrm{r}_{\text {tabel }}$ pada $\mathrm{df}=\mathrm{n}-5$ dalam penelitian ini mempunyai nilai (78-5) dan probabilitas 0,05 $\quad r_{\text {hitung }}>r_{\text {tabel, }}$ artinya bahwa semua diperoleh $r_{\text {tabel }}=0,2272$ menunjukan indikator dikatakan valid. bahwa semua indikator yang digunakan untuk mengukur variabel

\section{Uji Reliabilitas}

\begin{tabular}{|c|c|}
\hline $\mathrm{R}_{\text {hitung }}$ & 0,71413 \\
\hline $\mathrm{R}_{\text {tabel }}$ & 0,2272 \\
\hline Reliabilitas & Reliabel \\
\hline
\end{tabular}

Sumber: Exel 2007, data quisoner

Berdasarkan tabel diatas menunjukan bahwa semua nilai Cronbach's Alpha >0,2272. Artinya semua variabel pada penelitian ini dinyatakan reliabel sehinga dinyatakan baik untuk penelitian.

\section{Uji Regresi Linier Berganda}

Dependent Variable: KEPUASAN PELANGGAN

Method: Least Squares

Date: 04/02/18 Time: 06:22

Sample: 178

Included observations: 78

\begin{tabular}{ccccc}
\hline \hline Variable & Coefficient & Std. Error & t-Statistic & Prob. \\
\hline \hline C & 2.639191 & 1.040259 & 2.537051 & 0.0133 \\
KEANDALAN & 0.267399 & 0.056052 & 4.770569 & 0.0000 \\
JAMINAN & 0.140013 & 0.036511 & 3.834823 & 0.0003 \\
BUKTI_FISIK & 0.176165 & 0.053665 & 3.282689 & 0.0016 \\
EMPATI & 0.229928 & 0.051017 & 4.506892 & 0.0000 \\
DAYA_TANGGAP & 0.006682 & 0.043758 & 0.152692 & 0.8791 \\
\hline \hline
\end{tabular}

Sumber: Eviews 9, data quisoner 
Berdasarkan tabel di atas, hasil dari regresi berganda diatas maka dapat di bentuk suatu persamaan model regresi berganda sebagai berikut :

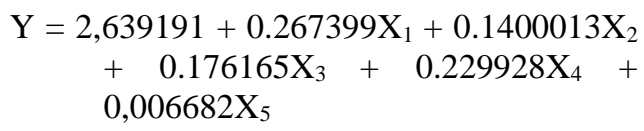

Dari analisis di atas dapat disimpulkan bahwa, variabel yang memiliki pengaruh lebih dominan terhadap keputusan pembelian adalah variabel reliability $\left(\mathrm{X}_{1}\right)$ karena memiliki nilai sebesar 0.267399 . Dengan demikian dapat dijelaskan bahwa hipotesis yang menyatakan variabel kualitas pelayanan paling dominan terhadap kepuasan pelanggan menurut Sugiyono (2015).

\section{Koefisien Determinasi}

Dependent Variable: KEPUASAN PELANGGAN

Method: Least Squares

Date: 04/02/18 Time: 06:22

Sample: 178

Included observations: 78

\begin{tabular}{lrll}
\hline \hline R-squared & 0.644981 & Mean dependent var & 12.34615 \\
Adjusted R-squared & 0.620326 & S.D. dependent var & 0.937348 \\
S.E. of regression & 0.577572 & Akaike info criterion & 1.813836 \\
Sum squared resid & 24.01843 & Schwarz criterion & 1.995121 \\
Log likelihood & -64.73960 & Hannan-Quinn criter. & 1.886408 \\
F-statistic & 26.16116 & Durbin-Watson stat & 1.997515 \\
Prob(F-statistic) & 0.000000 & & \\
\hline
\end{tabular}

Sumber: Eviews 9, data quisoner

Dari analisis diatas diperoleh hasil perhitungan regresi yang dapat diketahui bahwa nilai koefisien determinasi $\left(R^{2}\right)$ yang diperoleh dari hasil $\mathrm{R}$ square sebesar 0.644981 . Dari nilai $R^{2}$ tersebut dapat ditarik kesimpulan bahwa variabel reliability (keaandalan), assurance (jaminan), tangible (bukti fisik) empathy (empati), dan responsiveness (daya tanggap) secara bersama-sama telah mampu menjelaskan atau menerangkan keragaman dari variabel terikat yaitu kepuasan pelanggan. Pengaruh variabel reliability (keaandalan), assurance (jaminan), tangible (bukti fisik), empathy (empati), dan responsiveness (daya tanggap) terhadap kepuasan pelanggan memberikan kontribusi sebesar $64,4 \%$ sedangkan sisanya sebesar $35,6 \%$ dipengaruhi oleh faktor lain yang tidak diteliti.

Hal ini sesuai jurnal Koestanto, Tri, Hari, et all (2015) Eva, Karla (2015), Khasanah, Imroatul (2010), dan Khatimah, Husnul (2010), Namun dalam jurnal Panjaitan, Januar, et all (2016) menolak jurnal sebelumnya bahwa pengaruh variabel reliability (X1), assurance (X2), tangible (X3) empathy (X4), dan responsiveness (X5) terhadap kepuasan pelanggan (Y) memberikan kontribusi sebesar $64,4 \%$ sedangkan sisanya sebesar $35,6 \%$ dipengaruhi oleh faktor lain yang tidak diteliti. 


\section{Uji t}

Dependent Variable: KEPUASAN PELANGGAN

Method: Least Squares

Date: 04/02/18 Time: 06:22

Sample: 178

Included observations: 78

\begin{tabular}{ccccc}
\hline \hline Variable & Coefficient & Std. Error & -Statistic & Prob. \\
\hline \hline C & 2.639191 & 1.040259 & 2.537051 & 0.0133 \\
KEANDALAN & 0.267399 & 0.056052 & 4.770569 & 0.0000 \\
JAMINAN & 0.140013 & 0.036511 & 3.834823 & 0.0003 \\
BUKTI_FISIK & 0.176165 & 0.053665 & 3.282689 & 0.0016 \\
EMPATI & 0.229928 & 0.051017 & 4.506892 & 0.0000 \\
DAYA_TANGGAP & 0.006682 & 0.043758 & 0.152692 & 0.8791 \\
\hline \hline
\end{tabular}

Sumber: Eviews 9, data quisoner

Dari hasil analisis uji t diperoleh nilai $t_{\text {hitumg }}$ reliability (4,77051), assurance $\quad(3,834823)$,tangible $(3,282689)$ empathy $(4,506892)$, dan responsiveness $(0,152692)$ sedangkan $t_{\text {tabel }}$ sebesar 1,99300 . Karena $t_{\text {hitung }}>t_{\text {tabel }}$ maka $H_{0}$ ditolak dan $H_{1}$ diterima artinya bahwa variabel bebas reliability (X1), assurance (X2), tangible (X3), empathy (X4), dan responsiveness (X5) secara parsial mempunyai pengaruh yang signifikan terhadap kepuasan pelanggan (Y). Hal ini sesuai jurnal Koestanto, Tri, Hari, et. al (2015) Eva, Karla (2015), Khasanah, Imroatul (2010), dan Khatimah, Husnul (2010), Namun dalam jurnal Panjaitan, Januar, et. al (2016) menolak jurnal sebelumnya bahwa variabel bebas reliability (X1), assurance (X2), tangible (X3), empathy (X4), dan responsiveness (X5) secara parsial mempunyai pengaruh yang signifikan terhadap kepuasan pelanggan (Y).

\section{Uji F}

Dependent Variable: KEPUASAN PELANGGAN

Method: Least Squares

Date: 04/02/18 Time: 06:22

Sample: 178

Included observations: 78

\begin{tabular}{|c|c|c|c|}
\hline R-squared & 0.644981 & Mean dependent var & 12.34615 \\
\hline Adjusted R-squared & 0.620326 & S.D. dependent var & 0.937348 \\
\hline S.E. of regression & 0.577572 & Akaike info criterion & 1.813836 \\
\hline Sum squared resid & 24.01843 & Schwarz criterion & 1.995121 \\
\hline Log likelihood & -6473960 & Hannan-Quinn criter. & 1.886408 \\
\hline $\begin{array}{l}\text { F-statistic } \\
\text { Prob(F-statistic) }\end{array}$ & $\frac{26.16116}{0.000000}$ & Durbin-Watson stat & 1.997515 \\
\hline
\end{tabular}


Dari analisis uji $\mathrm{F}$ diperoleh nilai $F_{\text {hitumg }}$ sebesar 26,16116 sedangkan $F_{\text {tabel }}$ sebesar 2,50. Karena $F_{\text {hitung }}>F_{\text {tabel }}$ maka $H_{0}$ ditolak dan $H_{1}$ diterima artinya bahwa variabel bebas kualitas reliability (X1), assurance (X2), tangible (X3), empathy (X4), dan responsiveness (X5) secara simultan (bersama-sama) mempunyai pengaruh yang signifikan terhadap kepuasan pelanggan (Y). Hal ini sesuai dengan jurnal Koestanto, Tri, Hari, et all (2015), Eva, Karla (2015), Khasanah, Imroatul (2010), dan Khatimah, Husnul (2010), Namun dalam jurnal Panjaitan, Januar, et all (2016) menolak jurnal sebelumnya bahwa variabel bebas kualitas reliability (X1), assurance (X2), tangible (X3), empathy (X4), dan responsiveness (X5) secara simultan (bersama-sama) mempunyai pengaruh yang signifikan terhadap kepuasan pelanggan (Y).

\section{KESIMPULAN}

\begin{tabular}{lrr}
\multicolumn{1}{c}{ Dari } & hasil & penelitian \\
menunjukkan & bahwa & reliability, \\
assurance, tangible & empathy, \\
responsiveness, secara & positif
\end{tabular} berpengaruh terhadap kepuasan pelanggan. Dengan koefisien $64,4 \%$ yang menunjukkan bahwa kedua variabel kualitas pelayanan dan kepuasan pelanggan memilikik hubungan yang erat. Variabel reliability, assurance, tangible, empathy, responsiveness secara positif berpengaruh terhadap kepuasan pelanggan. memberikan pengaruh signifikan terhadap kepuasan pelanggan. Begitu pula dengan empathy juga memberikan pengaruh yang signifikan terhdap kepuasan pelanggan sesuai jurnal Tri, Hari, et all (2015), Eva, Karla (2015), Khasanah, Imroatul (2010), dan Khatimah, Husnul (2010). Namun variabel responsiveness tidak memiliki pengaruh yang signifikan terhadap kepuasan pelanggan sesuai Panjaitan, Januar, et all (2016). Dengan variabel yang paling dominan adalah Reliability nilai sebesar 0.267399.

\section{Daftar Pustaka}

Panjaitan Januar, et. al, 2016. Pengaruh Kualitas Pelayanan Terhadap Kepuasan Pelanggan Pada JNE Cabang Bandung. DeReMa Jurnal Manajemen Vol. 11 No. 2.

Karla, Eva, 2015. Analisis Pengaruh Kualitas Pelayanan Terhadap Kepuasan Kosumen Pada Matahari Departement Store. UG Jurnal Vol. 9 No. 09.

Koestanto, Tri Hari, et. al, 2015. Pengaruh Kualitas Pelayanan Terhadap Kepuasan Pelanggan Pada Bank Jatim Cabang Klampis Surabaya. Jurnal Ilmu \& Riset Manajemen Vol. 3 No. 10.

Wijyanto, 2016. Analisis Pengaruh Kualitas Pelyanan Terhadap Tinggi Rendahnya Nasabah Di Bank Syari'ah Mandiri Cabang Salatiga. Volume 7 Nomor 2.

Maskur, Muhammad, et. al, 2016. Analisis Pengaruh Kualitas Pelayanan, Harga, Dan Kepuasan Pelanggan Terhadap Loyalitas Pelanggan ( Studi 
Kasus Pada Bengkel Mobil Larasati Lumajang ). Jurnal Sains Manajemen \& Bisnis Indonesia Volume VI, No. 2, halaman $212-221$.

Khasanah, Imroatul, et. al, 2010. Analisis Pengaruh Kualitas Pelayananterhadap Kepuasan Konsumen RS St. Elisabeth Semarang. Aset, hal. 117-124 Vol. 12 No.2 ISSN 1693-928X.

Khatimah, Husnul (2010) yang berjudul Analisis Pengaruh Kualitas Pelayanan Terhadap Kepuasan Nasabah ( Studi Pada Nasabah BRI Cabang Semarang Pattimura ).

Hardiyati, Ratih, 2010. Analisis Pengaruh KualitasPelayanan Terhadap Kepuasan Konsumen Menggunakan Jasa Penginapan ( Villa ) Agrowisata Kebun Teh Pagilaran. Skripsi. Semarang : Universitas Diponogoro SemarangKotler, Philip, dan Kevin, Keller. 2008. Manajemen Pemasaran. Erlangga dengan Power Macpro. Jakarta.

Kotler, amstrong. 2008. Prinsipprinsip pemasaran 2. Edisi 12. Erlangga. Jakarta

Kotler, Philip dan Kevin Lane Keller. 2012. Marketing Management 13, New Jersey: Pearson Prentice Hall, Inc.

Sugiyono. 2015. Statistika Untuk Penelitian. Alfabeta, Bandung. 